\title{
An Empirical Study on Intelligent Rural Tourism Service by Neural Network Algorithm Models
}

\author{
Jingzhi Chen, ${ }^{1}$ Hongbo Xue $\mathbb{D}^{2},{ }^{2}$ and Sang-Bing Tsa ${ }^{3}{ }^{3}$ \\ ${ }^{1}$ Chongqing College of Finance and Economics, Chongqing 402160, China \\ ${ }^{2}$ School of Business Administration, Shanghai Lixin University of Accounting and Finance, Shanghai 201620, China \\ ${ }^{3}$ Regional Green Economy Development Research Center, School of Business, Wuyi University, Nanping, China
}

Correspondence should be addressed to Hongbo Xue; hongbo.xue@edhec.com

Received 28 September 2021; Revised 16 October 2021; Accepted 25 October 2021; Published 5 November 2021

Academic Editor: Zaoli Yang

Copyright (C) 2021 Jingzhi Chen et al. This is an open access article distributed under the Creative Commons Attribution License, which permits unrestricted use, distribution, and reproduction in any medium, provided the original work is properly cited.

\begin{abstract}
With the continuous development of social economy, tourism has become one of the many choices and is becoming more and more popular. However, it should be noted that how to provide high-quality and efficient tourism services is extremely important. This paper introduces the neural network algorithm and the optimal classification decision function, through unified combing, classification, and coding of scenic spots, to achieve the subclass classification of scenic spots, based on the optimal distribution function of random intelligent selection, and the formation of the corresponding scenic spots traversal clear tourism routes. The corresponding motivation iteration is obtained by using the corresponding travel route transmission, the best travel route is defined, the corresponding auxiliary decision support is provided, and the simulation experiment is carried out. The experimental results show that the neural network algorithm and the optimal classification decision function are effective and can support the intelligent decision assistance of rural tourism service.
\end{abstract}

\section{Introduction}

With the continuous development of social economy, tourism has become a more and more popular choice, especially in holidays as one of the important activities of many people [1]. In addition to the traditional natural features and cultural precipitation, rural tourism has gradually become an increasingly popular route in recent years $[2,3]$. In terms of differentiation, the city's tourism infrastructure construction is relatively perfect; from the tourism transportation facilities, tourism configuration, catering, and accommodation configuration are relatively intact. However, due to the weak infrastructure, rural tourism is deficient in food, accommodation, and other aspects to a certain extent, which needs further improvement $[4,5]$. For tourists, if they have a high evaluation of the whole place, they will have a high willingness to travel. These factors are easy to exist in the bus routes and road congestion of scenic spots, causing the interference of tourism activities [6,7]. Therefore, how to determine the best route according to the corresponding factors between scenic spots, maximize the benefits of tourism, and save the corresponding cost, for the provision of corresponding services is extremely important. The continuous implementation of rural revitalization policies has led to the transformation and development of more and more agricultural industries, and rural tourism has become an increasingly important choice due to its green and environmental protection $[8,9]$. More rural recreation, fishing and other activities have become popular, and smart tourism has also become the trump development direction of rural tourism and an important new development trend of tourism. At the same time, farmers are increasingly active in thinking. They are not limited to traditional services, but are oriented to more intelligent services. In addition to traditional tourism 
accommodation and food, they also provide farming and rural experience $[1,10]$.

However, it should be noted that, in the process of rural tourism development, due to the lack of important planning and preliminary investigation, there are many development problems. How to promote rural tourism, on the one hand, ensures normal and healthy development, and on the other hand, harmoniously coexists with the natural environment $[9,11,12]$. Therefore, in view of these situations, this paper introduced the neural network algorithm and the optimal classification decision function, and through the study of the topology relation network construction of rural scenic spots, tourist attractions are formed by random choice; according to the corresponding iterative interference factors analysis, the quantitative analysis of different tours as a decision aid to support the reasonable route and sorting and the choice of maximum as the best route aim to promote rural tourism and develop the local economy.

\section{Neural Network Algorithm and Optimal Classification Decision Function}

For neural network algorithm and the optimal classification decision function is concerned, the first is geared to the needs of tourism route of the corresponding planning; for the tourists, the most important consideration is the time and effort, the need for a limited time to maximize the corresponding travel, realizing the maximization of tourist routes, through the fixed time, and visiting more classic. Therefore, how to choose tourist attractions is extremely important. A simple one-way tourist route cannot be arranged simply and directly. On the one hand, it will miss the corresponding classical scenic spot information, and on the other hand, it will waste too much time and lead to the waste of travel time.

\subsection{Random Selection Model of Scenic Spot Classification} Code. According to the corresponding rural scenic spots, the classification code selection analysis of scenic spots is made clear, and the corresponding scenic spots with feature points are set. The scenic spots are classified into CLASS $h$ and expressed as $T=\left\{V_{r} \mid r \in(0, h], r \in Z^{+}\right\}$by the formula. The subset of scenic spots is represented by $V_{r}$, and scenic spots contain the corresponding rural scenic spot elements. The distribution function of the corresponding random variable is calculated and expressed as follows:

$$
F(x)=\frac{x-a}{b-a}, \quad x \in[a, b] .
$$

Set the corresponding classical classification subset to be represented by vector $B_{r}=\left(V_{r} G_{1}, V_{r} G_{2}, \ldots, V_{r} G_{e_{\alpha}}\right)$.

On this basis, the corresponding element matrix $\mathrm{A}$ of rural scenic spots is established, and the specific calculation is shown as follows:

$$
A=\left[\begin{array}{cccccc}
V_{r} G_{1} & \ldots & V_{r} G_{\min e_{\alpha}} & 0 & 0 & 0 \\
& & B_{2} & 0 & 0 & 0 \\
\vdots & & & B_{3} & 0 & 0 \\
& & & & & \vdots \\
V_{r} G_{1} & \ldots & & & V_{r} G_{\min e_{\alpha}-1} & V_{r} G_{\min e_{\alpha}}
\end{array}\right] .
$$

For tourists to select the corresponding rural scenic spots randomly, select the corresponding scenic spots intelligently and carry out random number coding. For tourists, they can provide reasonable sorting of scenic spots and set up corresponding travel routes according to their interest demands and time costs. Generally speaking, the number of scenic spots should not exceed 4 per day, and they should be reminded of their travel itinerary.

Step 1. Select several elements of the corresponding rural scenic spots, set them into the corresponding rural scenic spots subset class, and determine the categories and corresponding numbers of scenic spots based on the tourists' time and interest $[13,14]$.

Step 2. Set the corresponding scenic spot category, set the corresponding tourism subset elements, and provide the corresponding number of scenic spots.

Step 3. On the basis of Step 2, the corresponding random number of neural network is used to calculate, and the corresponding random code is produced, which is represented by $\alpha \in[0,1)$. If $3 \omega$ is 1 , the corresponding iteration is completed; if not, the corresponding iteration continues.

Step 4. Return to Step 3. The corresponding scenic spots are called separately, and the corresponding random number is generated, and the corresponding scenic spots are calculated until all the scenic spots are calculated.

The neural network algorithm is used to generate random numbers, and the specific calculation of scenic spots is shown as follows:

$$
m=\sum_{\beta=1}^{h} m_{\beta} .
$$

2.2. Neural Network Algorithm Modeling. Based on the classification of scenic spots, the modeling of the neural network algorithm is carried out. Firstly, according to the requirements of various input and single output, the neuron model is used to process and transmit to the next neuron according to the corresponding external signals. The specific neuron model is shown in Figure 1:

Set the corresponding input to $I_{1}, I_{2}, \ldots, I_{n}$; neuron output is set to $O_{i}$; the connection strength between neurons is represented by $W_{i j}$. Set $\theta_{i}$ to the threshold. In addition, using $\mathrm{F}(x)$ as the action function, specific formulas can be calculated according to corresponding neurons, as follows: 


$$
O_{i}=f\left(\sum_{j} W_{i j} I_{j}-\theta_{i}\right), \quad i=1,2, \ldots, n .
$$

The specific calculation algorithm is as follows:

(i) Definition 1: set the corresponding motivation influence factor as $\mathrm{K}$, that is, the index of the influence of tourists' interest on the tourism motivation of selected scenic spots $[15,16]$.

(ii) Definition 2: set the corresponding motivation influence fluctuation; when a scenic spot finishes the tour, the corresponding objective and subjective conditions are the corresponding motivation [17-19].

(iii) Definition 3: set the influence factor threshold. If the influence factor plays a promoting role, set the value to be positive. If it has side effects, set it to negative.

(iv) Definition 4: motivation iteration valuetransmission of the next scenic spot according to the corresponding scenic spot [20-22].

According to the corresponding scenic spots, corresponding tourism route neurons are established, and each neuron is set as a scenic spot. The motivation influencing factors of tourism cause corresponding fluctuations, as shown in Figure 2.

On the basis of Figure 2, the corresponding one-way tourism neural network model is established, as shown in Figure 3:

The iterative function I $(t)$ that affects $\forall Q_{u}$ tourism motivation is the volatility weight caused by $p$ motivation factors. Calculate the iterative action value of $A_{m}^{m}$ kinds of tourism route motivation to get $\max I_{(w)}$, where $w \in\left(0, A_{m}^{m}\right] \in Z^{+}$is the iterative action value of the best tourism route motivation of intelligent planning. Set the matrix to $M_{1} \times M_{2}$, and the descending iterative action value matrix $M$ of the dimensional tourism route arranges the element value $I_{(w)}$ in descending order, which satisfies $M_{1} \times M_{2}=A_{m}^{m}$, as follows:

$$
I_{u}=\sum_{0<u \leq m, 0<v \leq p} H_{v, u} I_{u-1}+\eta_{v, u} .
$$

\subsection{SVM Regression Problem for Decision Function Reduction.} Given $N$ training samples $\left\{\left(x_{i}, y_{i}\right)\right\}_{i=1}^{N}$, set the input vector to $x_{i} \in R^{n}$ and the output to $y_{i} \in R$. Construct the corresponding nonlinear mapping and establish the corresponding high-dimensional linear mapping as follows:

$$
\begin{array}{r}
\min _{w, b, \xi}\left[\frac{1}{2}\|w\|^{2}+C \sum_{i=1}^{n} \xi_{i}\right], \\
\text { s.t. } y_{i}\left(\left\langle\phi\left(x_{i}\right), w\right\rangle+b\right) \geq 1-\xi_{i}, \quad \xi_{i} \geq 0, i \in N .
\end{array}
$$

The expression of the decision function can be written in the following form:

$$
\begin{aligned}
y(x) & =\sum_{i=1, i \neq k}^{N} \alpha_{i} K\left(x, x_{i}\right)+\alpha_{k} \sum_{i=1, i \neq k}^{N} c_{i} K\left(x, x_{i}\right)+b \\
& =\sum_{i=1, i \neq k}^{N}\left(\alpha_{i}+\alpha_{k} c_{i}\right) K\left(x, x_{i}\right)+b .
\end{aligned}
$$

The decision function is simplified in the form of order reduction $[17,18]$.

2.4. SVM Parameter Optimization. Lagrange multiplier method is adopted to solve the above constraint problems, as follows:

$$
J(\omega, b, \alpha)=\frac{1}{2} w^{T} w-\sum_{i=1}^{N} \alpha_{i}\left[y_{i}\left(w \cdot x_{i}+b\right)-1\right],
$$

where $\alpha$ is the Lagrange multiplier. According to the optimality condition, the dual question of the original problem can be obtained as follows:

$$
\begin{aligned}
& \max _{a} Q(a)=J(w, b, \alpha)=\sum_{i=1}^{N} \alpha_{i}-\frac{1}{2} \sum_{i=1}^{N} \sum_{j=1}^{N} \alpha_{i} \alpha_{j} y_{i} y_{j} x_{i}^{T} x_{j}, \\
& \text { s.t. } \sum_{i=1}^{N} \alpha_{i} y_{i}=0, \quad \alpha_{i} \geq 0 .
\end{aligned}
$$

The solution of formula (9) is obtained by training data set.

In order to obtain the best SVM parameters, the PSO algorithm is used to optimize the penalty parameter C, insensitive loss coefficient $G$, and kernel function $\sigma$ parameters of SVM [19]. The final SVM model expression is shown as follows:

$$
y(x)=\omega^{T} \varphi(x)+b .
$$

2.5. Linearization of SVM Model. Let $n=n_{u}+n_{y}$, select RBF kernel function, which can be written as follows:

$$
\begin{aligned}
y(x)= & C+b_{1} u(k-1)+\cdots+b_{n_{u}} n\left(k-n_{u}\right) \\
& -a_{1} y(k-1)-\cdots-a_{n_{y}} y\left(k-n_{y}\right) .
\end{aligned}
$$

Equation (11) can be used as the prediction model of predictive control.

The performance index function is shown as follows:

$$
\begin{aligned}
\min J(k)= & E\left\{\sum_{j=N_{1}}^{N_{2}}\left[y_{r}(k+j)-y_{p}(k+j)\right]^{2}\right\} \\
& \times \sum_{j=1}^{N u} \lambda_{j}[\Delta u(k+j-1)]^{2} .
\end{aligned}
$$

The formula for particle updating is shown as follows: 


$$
\left\{\begin{array}{l}
v_{i}(t+1)=\lambda\left\{\theta v_{i}(t)+c_{1} r_{1}\left[p_{\text {best }}-x_{i}(t)\right]+c_{2} r_{2}\left[g_{\text {best }}-x_{i}(t)\right]\right\} \\
x_{i}(t+1)=x_{i}(t)+v_{i}(t+1)
\end{array}\right.
$$

Therefore,

$$
\begin{aligned}
& \lambda=\frac{1}{\left|2-C-\sqrt{C^{2}-4 C}\right|}, \\
& C=c_{1}+c_{2}, \theta=\theta_{i n i}-\frac{t\left(\theta_{i n i}-\theta_{\text {en } d}\right)}{m},
\end{aligned}
$$

where $\theta_{\text {ini }}$ and $\theta_{\text {en } d}$ are the initial and final values of inertia weight, $c 1$ and $c 2$ are learning factors, and $M$ is the maximum number of iterations. The magnitude of inertia weight represents the global and local search capability of the algorithm. The learning factors $\mathrm{c} 1$ and c2 reflect the information exchange between particle swarm.

\section{Algorithm Design}

Step 5. Firstly, classify the types of existing scenic spots in rural areas and encode the subunits of corresponding scenic spots, respectively, to build the corresponding scenic spot matrix.

Step 6. Rank the corresponding rural scenic spots.

(1) Random number generation of uniform distribution function is carried out according to the corresponding optimal classification decision function, and iteration is conducted to generate the element attractions with different codes

(2) Further call the optimal classification decision function to generate the random number of the uniform distribution function and carry out the second iteration to generate the element attractions with different codes

Make $h$ calls, use the optimal classification decision function to generate the random number of the uniform distribution function, and carry out the $h$ iteration to generate the element attractions with different codes. The rural scenic spots are included in the evaluation, and the corresponding rural tourism route vector is finally formed.
Step 7. Identify the corresponding tourism motivation impact factor $K$ and determine the corresponding motivation impact and impact factor fluctuation.

(1) If the tourists have no special requirements for the order, the fourth step should be directly transferred

(2) If the tourists have clear requirements on the route of the tour, it shall be carried out according to the corresponding considerations

Step 8. Iterate $A_{m}^{m}$ travel routes are formed by permutation and combination of $m$-dimensional travel route basis vector $Q$, and the action value of motivation iteration is calculated.

3.1. Scenic Spot Selection. According to the different scenic spots in the rural-urban fringe, the corresponding scenic spots can be classified into four categories, V1 to V4, as shown in Table 1:

Figure 4 shows the spatial distribution of selected scenic spots, and the constructed element scenic spot matrix is shown as follows:

$$
A=\left[\begin{array}{cccccccc}
V_{1} G_{1} & V_{1} G_{2} & V_{1} G_{3} & V_{1} G_{4} & V_{1} G_{5} & V_{1} G_{6} & V_{1} G_{7} & V_{1} G_{8} \\
V_{2} G_{1} & V_{2} G_{2} & V_{2} G_{3} & V_{2} G_{4} & 0 & 0 & 0 & 0 \\
V_{2} G_{1} & V_{3} G_{3} & V_{3} G_{3} & V_{3} G_{4} & V_{3} G_{5} & V_{3} G_{6} & V_{3} G_{7} & 0 \\
V_{4} G_{1} & V_{4} G_{4} & V_{4} G_{3} & V_{4} G_{4} & V_{4} G_{5} & V_{4} G_{6} & 0 & 0
\end{array}\right] .
$$

In order to verify the effect of decision function reduction on the number of support vectors, 4000 data points in the database are used for verification.

3.2. Analysis of Example Results and Decision Support. Set the corresponding impact factor fluctuation threshold, as shown in Figure 5.

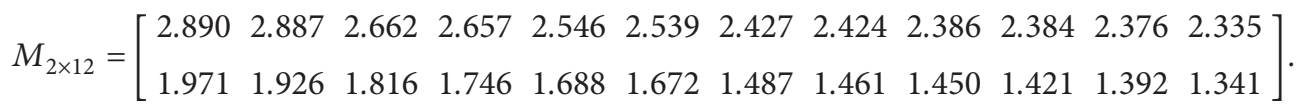

According to the scenic spots selected by tourists, determine the $A_{4}^{4}$ tourism route scheme. The first 6 items of the output value are taken as intelligent decision support cases to export the tourism order map and tourism roadmap (see Figure 6). The optimal travel route of the matrix $M$ in descending order of elements is
(2) $\longrightarrow$ (1) $\longrightarrow$ (3) $\longrightarrow$ (4), and the iterative travel route motivation value is the largest. Tourists can easily obtain the maximum motivation benefit when choosing this travel route (see Figure 6).

According to the results of the example in Figure 5 and the first six cases, the following decision support is provided: 


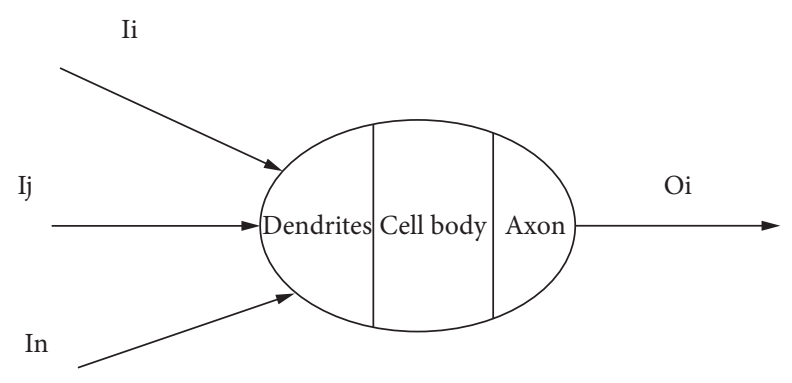

FIGURE 1: MP neuron model.

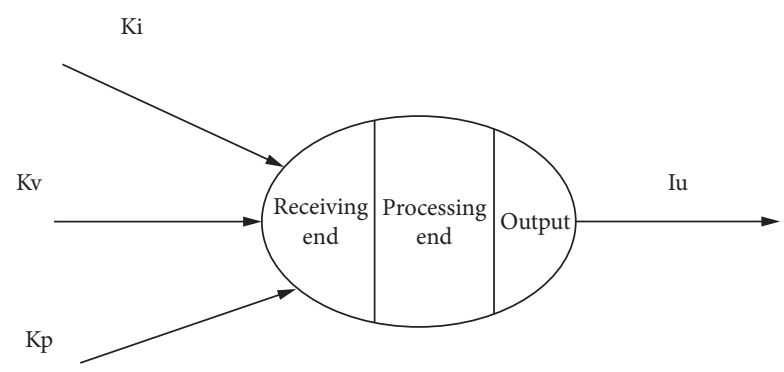

FIgURE 2: Neuron model of tourist route.

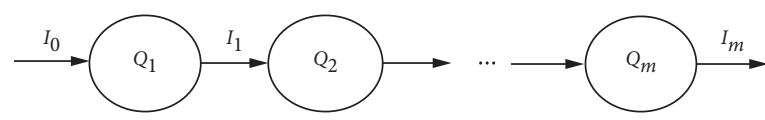

FIGURE 3: One-way neural chain model of tourist routes.

TABLE 1: Scenic spot coding of scenic spot subset elements.

\begin{tabular}{lc}
\hline Attractions subset & Element attraction code \\
\hline V1 & V1G1 Park 1, V1G2 Park 2, V1G3 Park 3, V1G4 Forest Park, V1G5 Botanical Garden \\
V2 & V2G1 Happy Garden 1, V2G2 Happy Garden 2, V2G3 Happy Garden 3, V2G4 Happy Garden 4 \\
V3 & V3G1 Museum, V3G3 Memorial, V3G4 Art Museum, V3G5 Science Museum \\
V4 & V4G1 Square 1, V4G Square 2, V4G3 Square 3 \\
\hline
\end{tabular}

(1) For tourists, there are no specific requirements on tourist routes and scenic spots. On the whole, the best route for route 1 is downward (2) $\longrightarrow$ (1) $\longrightarrow$ (3) $\longrightarrow$ (4), and the second is upward (4) -- (3) -- (1) -- (2)

(2) For tourists, there are certain requirements on tourist routes and scenic spots

Route 2 tours along the way; choosing the downward (2) $\longrightarrow$ (1) $\longrightarrow$ (3) $\longrightarrow$ (4) best route can obtain the maximum motivation benefit and choose the upward (4) -- (3) -- (1) -(2) route.

Route 3: (1) $\longrightarrow$ (2) $\longrightarrow$ (3) $\longrightarrow$ (4) for sightseeing in the morning and shopping and leisure in the afternoon. Do not consider the route, shopping in the morning leisure, afternoon sightseeing, choose (4) $\longrightarrow$ (3) $\longrightarrow$ (2) $\longrightarrow$ (1) route.

For route 4, take a side trip in the morning and shopping and leisure in the afternoon. Choose the best route down (2) $\longrightarrow$ (1) $\longrightarrow$ (3) $\longrightarrow$ (4) or the best route down (2) $\longrightarrow$ (1) $\longrightarrow$ (4) $\longrightarrow$ (3). Consider the route, shopping and leisure in the morning, sightseeing in the afternoon, and choose the up (4) $\longrightarrow$ (3) $\longrightarrow$ (1) $\longrightarrow$ (2) route or up (3) $\longrightarrow$ (4) $\longrightarrow$ (1) $\longrightarrow$ (2) route.

The simulation results show that the influence of tourists' motivation is great, and the neural network algorithm and optimal classification decision function are effective.

\section{Intelligent Construction Path of Rural Tourism Service}

In order to further realize the intelligent support of rural tourism services, corresponding measures should be taken to establish "man and nature" countermeasures.

4.1. Basic Ideas of Intelligent Construction of Rural Tourism Service. Rural tourism service of intelligent building should be corresponding resources, widen and update the corresponding information construction, according to the character of tourists for informatization construction, using 


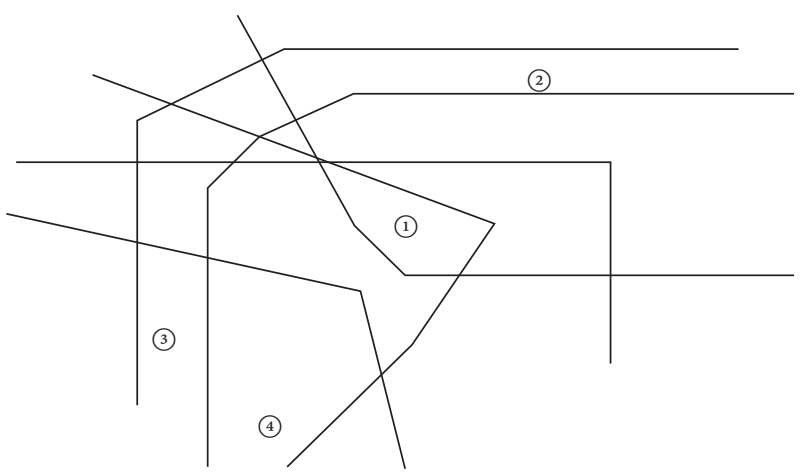

Figure 4: Spatial distribution of selected scenic spots.

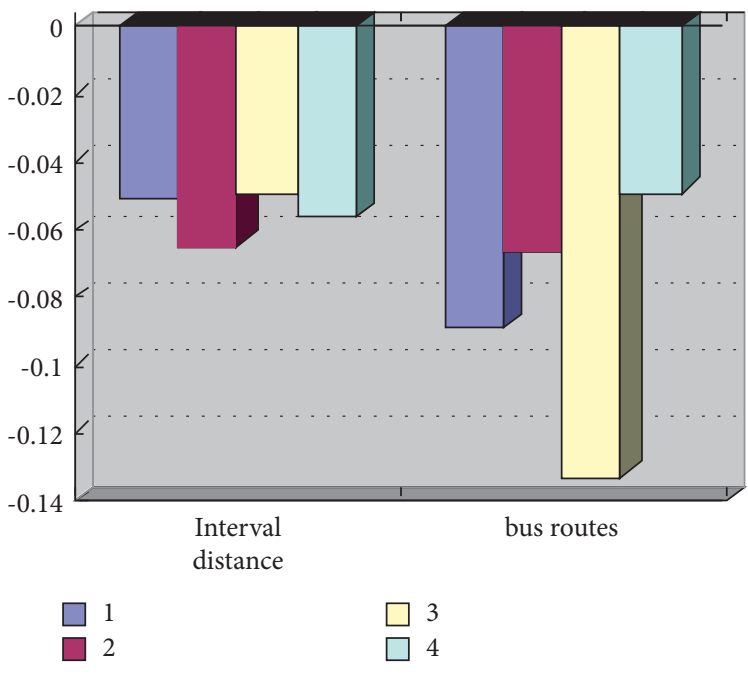

FIGURE 5: Fluctuation threshold of influencing factor $\eta$ parameter.

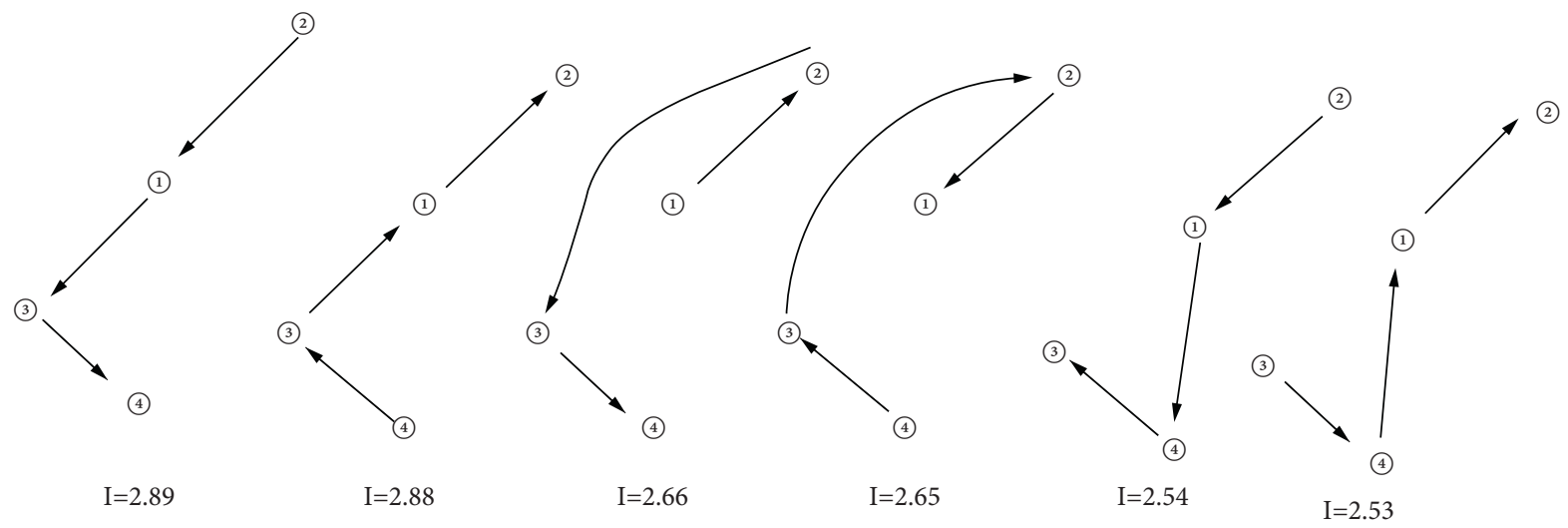

Figure 6: 6 elements of the tourism routes.

the corresponding cloud computing, Internet of things, big data, such as technology, improve the corresponding rural tourism service management, improve the corresponding tourism configuration, and break through the traditional travel restrictions.
4.2. Specific Methods of Intelligent Construction of Rural Tourism Service. In the tour, VR, RFID, and other technologies can be used to understand the equipment. After the tour, the corresponding equipment or website can be used to give feedback on the tour. Good feedback can be used as an 
example of publicity, while bad information can be used as a basis for improving service quality.

\section{Conclusions}

With the continuous development of social economy, rural tourism has become an important tourism destination, so how to make an important choice is extremely important. In this paper, the neural network algorithm and the optimal classification decision function are introduced. The simulation results show that the neural network algorithm and the optimal classification decision function are effective and can support the intelligent decision assistance of rural tourism service.

\section{Data Availability}

The data used to support the findings of this study are included within the article.

\section{Conflicts of Interest}

The authors declare no conflicts of interest.

\section{Acknowledgments}

This work was supported by Chongqing College of Finance and Economics.

\section{References}

[1] R. Wang, "Research on rural tourism based on intelligent tourism information service," IOP Conference Series: Materials Science and Engineering, vol. 750, no. 3, pp. 120-126, 2020.

[2] G. Han, I. Ryu, and I. Ryu, "A Study on the Relationship of Rural tourism service quality, experience, image, satisfaction, and loyalty," Journal of Tourism Management Research, vol. 24, no. 7, pp. 449-472, 2020.

[3] G. Song, S. Nam, S. Nam, and D. Kim, "A study on the effects of rural tourism service quality on flow and satisfaction, revisit intention," Journal of Tourism Management Research, vol. 25, no. 1, pp. 199-220, 2021.

[4] J. K. Ebrek and Doctoral Dissertation Summary, "Service quality measurement in rural tourism: an application of modified RURALQUAL model," Tourism and Hospitality Management, vol. 26, no. 4, pp. 1-8, 2020.

[5] F. H. Giray, B. Kadakoğlu, and F. Çetin, "Rural tourism marketing: lavender tourism in Turkey," Ciência Rural, vol. 49, no. 2, pp. 56-63, 2019.

[6] W. Huyan and J. Li, "Research on rural tourism service intellectualization based on neural network algorithm and optimal classification decision function," Journal of Ambient Intelligence and Humanized Computing, vol. 5, no. 2, pp. 1-21, 2021.

[7] G. Perić, S. Dramićanin, and M. Gašić, "Impact of service quality on satisfaction and loyalty of tourists in rural tourism of Šumadija and Western Serbia," Ekonomika Poljoprivrede, vol. 67, no. 4, pp. 1071-1086, 2020.

[8] S. Markovi and J. K. Ebrek, "Service quality measurement in rural tourism: application of RURALQUAL model," Academica Turistica - Tourism and Innovation Journal, vol. 13, no. 2, pp. 1-8, 2020.
[9] N. Rahmawati, L. A. Permadi, and B. H. Rinuastuti, “The influence OF attraction, location, and service quality $\mathrm{ON}$ revisit intention to sesaot rural tourism," Jmm Unram Master Of Management Journal, vol. 10, no. 1, pp. 43-50, 2021.

[10] T. H. Hwang and J.-H. Lee, "A study on the effect of relationship marketing on service quality, customer satisfaction and loyalty of rural tourism villages," Journal of Tourism and Leisure Research, vol. 32, no. 3, pp. 169-193, 2020.

[11] T. W. Nugroho, N. Hanani, and S. Sujarwo, "Post-tourism in booming Indonesian rural tourism industry: a social representation theory approach," Journal of Environmental Management and Tourism, vol. 1, no. 49, pp. 288-301, 2021.

[12] L. J. Yin, N. Zhang, and Z. Y. Chang, "Study on the impact of tourism quality perception on tourists' environmentally responsible behaviour in rural tourism areas," IOP Conference Series: Earth and Environmental Science, vol. 626, no. 1, pp. 115-123, 2021.

[13] M. R. Islam, "Community-based rural tourism development: a conceptual framework for Bangladesh," Journal of Service Research, vol. 7, no. 4, pp. 109-117, 2021.

[14] G. Mohanta, S. Sahoo, and P. S. Su Bb Arao, "Sustainable rural tourism development as a tool for reducing rural migration: a case study ON selected districts OF odisha," Gazi University Journal of Science, vol. 33, no. 11, pp. 11-21, 2020.

[15] M. Xu, "The study on tourist preference of wuyuan rural tourism based on web text analysis," Journal of Service Science and Management, vol. 13, no. 4, pp. 649-658, 2020.

[16] Y. Zhao, Y. Han, and Y. Wang, "How to establish the wisdom of rural tourism based on "Internet +": taking coastal areas in shandong province for example," Journal of Coastal Research, vol. 103, no. sp1, pp. 1047-1056, 2020.

[17] L. Zhou, "Analysis of factors that tourists attach importance to rural tourism image_- taking rural tourism in ningde region as example," Journal of Contemporary Educational Research, vol. 4, no. 9, pp. 54-60, 2020.

[18] C. H. Chin, M. C. Lo, Z. b. Razak, P. Pasbakhsh, and A. A. Mohamad, "Resources confirmation for tourism destinations marketing efforts using PLS-MGA: the moderating impact of semirural and rural tourism destination," Sustainability, vol. 12, no. 17, pp. 6787-6794, 2020.

[19] R. Liu and T. C. Wong, "Rural tourism in globalizing beijing: reproduction of the mountainous suburbs into a new space of leisure consumption," Sustainability, vol. 11, no. 6, pp. 59-69, 2019.

[20] C.-C. Huang, "User's segmentation on continued knowledge management system use in the public sector," Journal of Organizational and End User Computing, vol. 32, no. 1, pp. 19-40, 2020.

[21] N. Ramu, V. Pandi, J. D. Lazarus, and S. Radhakrishnan, "A novel trust model for secure group communication in distributed computing," Journal of Organizational and End User Computing, vol. 32, no. 3, pp. 1-14, 2020.

[22] A. Aderonke, "Oni, ugbedeojo musa, samuel oni. E-Revenue adoption in state internal revenue service: interrogating the institutional factors," Journal of Organizational and End User Computing, vol. 32, no. 1, pp. 41-61, 2020. 